\title{
THE EFFECT OF APPLICATION OF TOURNIQUETS TO THE LEGS ON CARDIAC OUTPUT AND RENAL FUNCTION IN NORMAL HUMAN SUBJECTS ${ }^{1,2}$
}

\author{
BY FRANCIS W. FITZHUGH, JR,, ${ }^{3}$ ROBERT L. MCWHORTER, JR., 4 E. HARVEY \\ ESTES, JR., J JAMES V. WARREN, AND ARTHUR J. MERRILL \\ (From the Renal Laboratory, Department of Medicine, and from the Department of Physiology, \\ Emory University School of Medicine and the Medical Service, \\ Grady Memorial Hospital, Atlanta, Ga.)
}

(Submitted for publication May 5, 1952; accepted July 1, 1953)

When blood is pooled in the lower extremities by the application of tourniquets at subdiastolic pressures to the thighs, prompt reductions occur in effective renal plasma flow (RPF), glomerular filtration rate (GFR) and renal excretion of water and electrolytes $(1,2)$. Similar alterations in renal function have been shown to occur in chronic congestive heart failure (3) and in head-up tilting of the normal subject (4). Since venous congestion of the lower extremities is demonstrable in all of the above situations, it has been proposed that this factor may be causally related to the functional disturbances observed in the kidney. This study represents an investigation of the pathogenesis of the changes in kidney function which occur when blood is pooled in the lower extremities by tourniquets, particularly in regard to the possible role of cardiac output.

\section{METHODS AND PROCEDURES}

All subjects were hospital patients who presented no evidence of cardiovascular or renal disease by history, physical examination and routine laboratory procedures. Studies were performed in the morning after at least 12 hours of fasting and one hour of complete bed rest. Phenobarbital, $0.1 \mathrm{Gm}$., and codeine sulfate, $64 \mathrm{mg}$., were given orally one hour prior to initiation of the procedure, and venipunctures were performed under local metycaine anesthesia. In no case was the subject unduly apprehensive.

1 Presented in preliminary form before the American Physiological Society, Augusta, Georgia, September 14, 1949.

2 This investigation was supported in part by a research grant from the National Heart Institute, of the National Institutes of Health, Public Health Service, and in part by a grant from the A. H. Robbins Co.

8 A. H. Robbins Co. Medical Research Fellow.

4 Joseph B. Whitehead Medical Research Fellow.

5 Life Insurance Medical Research Fellow.
Unless otherwise stated, hydration of the subject was accomplished by the oral administration of $200 \mathrm{ml}$. of water every 30 minutes. This was started at least one hour prior to onset of the observations and was continued until the end of the last study period. All of the patients were receiving the regular hospital diet.

RPF and GFR were determined using sodium paraaminohippurate and inulin, respectively, as described by Smith, Goldring, and Chasis (5). Clearance periods ranged from 8 to 18 minutes with an average of 11 minutes. In most experiments, blood samples for renal clearance studies were withdrawn through the cardiac catheter, the tip of which lay in either the pulmonary artery or the right atrium. In the others, they were collected from the antecubital vein. Para-aminohippurate was determined by the method of Bratton and Marshall (6) except that plasma proteins were precipitated with cadmium sulfate instead of trichloroacetic acid. Inulin was determined by the Harrison modification (7) of the

TABLE I

The effect of venous constricting leg tourniquets on cardiac index in ten normal subjects

\begin{tabular}{cccc}
\hline & \multicolumn{3}{c}{ Cardiac indext } \\
\cline { 2 - 4 } Subject & Control & $\begin{array}{c}\text { Tourniquets } \\
\text { on }\end{array}$ & $\begin{array}{c}\text { Tourniquets } \\
\text { off }\end{array}$ \\
\hline B. J. & 2.7 & 2.5 & 2.9 \\
E. F. & 4.0 & 2.7 & 3.6 \\
G. H. & 2.4 & 2.5 & 2.7 \\
E. D. & 2.2 & 1.8 & 2.0 \\
J. H. & 3.6 & 3.8 & 3.4 \\
K. B. & 2.6 & 2.3 & 2.6 \\
T. H. & 3.6 & 3.0 & 3.7 \\
C. G. & 4.2 & 3.4 & 3.9 \\
E. C. & 4.3 & 2.8 & 3.0 \\
N. A. & 5.2 & 2.8 & 6.0 \\
Mean & 3.5 & 2.8 & 3.4 \\
Per cent of control & 100 & 80 & 97 \\
S.E. & 0.3 & 0.2 & 0.3 \\
P value & & $<0.02$ & $>0.5$ \\
\hline
\end{tabular}

* Tip of catheter in right atrium. In all other subjects the catheter was in the pulmonary artery.

$\dagger$ Control cardiac index determinations were all made at least 35 minutes before application of tourniquets. Tourniquet values were obtained 21-35 minutes after application of tourniquets. Final determinations were made 14-36 minutes after release of tourniquets. 
method of Alving, Rubin, and Miller (8). Urine sodium concentration was measured with the Perkin-Elmer Model 52A flame photometer using lithium as an internal standard. All sodium excretion values are expressed in microequivalents per minute.

Cardiac output was determined by the direct Fick method. Samples of mixed venous blood from the right atrium or pulmonary artery were obtained from an inlying catheter introduced into the venous system through the antecubital vein $(9,10)$. In 8 of the 10 cardiac output studies the tip of the catheter lay in the pulmonary artery. The catheter tip was in the right atrium in the remaining two subjects. A sample of mixed venous blood was saturated with air and its oxygen content determined according to the method of Van Slyke and Neill (11). Ninty-five per cent of this value was taken as the oxygen content of arterial blood. Gasometric analyses on three-minute samples of expired air were performed by the method of Haldane (12).
In all studies, standard blood pressure cuffs were applied to the lower extremities as near to the trunk as possible. After at least two control renal clearance periods and one control cardiac output determination, the cuffs were inflated to a level just below diastolic pressure for periods ranging from 20 to 47 minutes. No subject complained of appreciable discomfort as a result of the tourniquets.

Sixteen studies were carried out in nine male and five female subjects. In the majority of the experiments an attempt was made to determine simultaneously cardiac output, RPF, GFR, urine sodium excretion, and urine volume. Due to technical difficulties this was possible in only two subjects. The following individual data were obtained: RPF in nine, GFR in eight; urine sodium excretion in nine; urine volume in nine, and cardiac output in ten. The cardiac index and renal function data are presented in Tables I and II, respectively.

Statistical analysis of the data was performed accord-

TABLE II

The effects of venous constricting leg tourniquets on effective renal plasma flow, glomerular filtration rate, sodium excretion, and urine volume in normal subjects

\begin{tabular}{|c|c|c|c|c|c|c|c|c|c|}
\hline \multirow[b]{2}{*}{ Patient } & \multicolumn{2}{|c|}{ Control } & \multicolumn{4}{|c|}{ Tourniquets on } & \multicolumn{3}{|c|}{ Tourniquets off } \\
\hline & Indiv. & Avg.* & $1 \dagger$ & 2 & 3 & 4 & 1 & 2 & 3 \\
\hline \multicolumn{10}{|c|}{ Renal plasma flow (ml./min./1.73 sq. m.) } \\
\hline J. D. & $\begin{array}{l}621 \\
686 \\
679\end{array}$ & 662 & 662 & 486 & 492 & 526 & 403 & 466 & \\
\hline L. L. & $\begin{array}{l}499 \\
480\end{array}$ & 490 & 455 & 421 & & & 448 & 516 & \\
\hline W. D. -1 & $\begin{array}{l}778 \\
706\end{array}$ & 742 & 750 & 789 & 727 & 622 & 580 & 900 & 905 \\
\hline W. D. -2 & $\begin{array}{l}663 \\
637\end{array}$ & 650 & 429 & 524 & 524 & & 457 & 478 & \\
\hline N. A. & $\begin{array}{l}568 \\
548\end{array}$ & 558 & 529 & 576 & 350 & 275 & 548 & 525 & 440 \\
\hline B. J. & $\begin{array}{l}612 \\
543\end{array}$ & 578 & 543 & 510 & 494 & 413 & 583 & 691 & 557 \\
\hline H. W. & $\begin{array}{l}551 \\
584\end{array}$ & 568 & 496 & 559 & 316 & & 594 & 545 & \\
\hline J. H. & $\begin{array}{l}558 \\
473\end{array}$ & 516 & 553 & 356 & 388 & 380 & 301 & 646 & \\
\hline G. H. & $\begin{array}{l}814 \\
739\end{array}$ & 777 & 518 & 512 & 588 & & 603 & 674 & \\
\hline $\begin{array}{c}\text { Mean } \\
\text { Per cent of control }\end{array}$ & & $\begin{array}{l}616 \\
100\end{array}$ & $\begin{array}{r}548 \\
89\end{array}$ & $\begin{array}{r}526 \\
85\end{array}$ & $\begin{array}{r}485 \\
79\end{array}$ & $\begin{array}{r}443 \\
72\end{array}$ & $\begin{array}{r}502 \\
82\end{array}$ & $\begin{array}{r}605 \\
98\end{array}$ & \\
\hline S.E. & & 33 & 33 & 40 & 48 & 60 & 35 & 46 & \\
\hline $\mathbf{P}$ value & & & $<0.2$ & $<0.05$ & $<0.001$ & $<0.01$ & $<0.02$ & $<0.9$ & \\
\hline
\end{tabular}

* Average of control period values.

† Duration of the individual periods varied from 8 to 18 minutes with an average of 11 minutes. Therefore each column on the chart may be considered as approximately an 11-minute period. 
TABLE II-Continued

\begin{tabular}{|c|c|c|c|c|c|c|c|c|c|}
\hline \multirow[b]{2}{*}{ Patient } & \multicolumn{2}{|c|}{ Control } & \multicolumn{4}{|c|}{ Tourniquets on } & \multicolumn{3}{|c|}{ Tourniquets off } \\
\hline & Indiv. & Avg.* & $1 \dagger$ & 2 & 3 & 4 & 1 & 2 & 3 \\
\hline \multicolumn{10}{|c|}{ Glomerular filtration rate $(\mathrm{ml} . / \mathrm{min} . / 1.73 \mathrm{sq} . \mathrm{m})}$. \\
\hline J. D. & $\begin{array}{l}154 \\
174\end{array}$ & 164 & 160 & 133 & 157 & 154 & 164 & 164 & \\
\hline L. L. & $\begin{array}{l}87 \\
99\end{array}$ & 93 & 115 & 117 & & & 112 & 128 & \\
\hline W. D. -1 & $\begin{array}{l}202 \\
185\end{array}$ & 194 & 245 & 204 & 234 & 148 & 208 & 238 & \\
\hline W. D. -2 & $\begin{array}{l}221 \\
181\end{array}$ & 205 & 128 & 173 & 173 & & 147 & 163 & \\
\hline B. J. & $\begin{array}{l}121 \\
122\end{array}$ & 122 & 110 & 113 & 118 & 96 & 127 & 159 & 114 \\
\hline H. W. & $\begin{array}{l}142 \\
158\end{array}$ & 150 & 129 & 140 & 109 & & 188 & 161 & \\
\hline J. H. & $\begin{array}{l}148 \\
126\end{array}$ & 137 & 126 & 86 & 100 & 108 & 75 & 179 & 176 \\
\hline G. H. & $\begin{array}{l}179 \\
150\end{array}$ & 165 & 120 & 123 & 156 & & 131 & 144 & \\
\hline $\begin{array}{c}\text { Mean } \\
\text { Per cent of control }\end{array}$ & & $\begin{array}{l}154 \\
100\end{array}$ & $\begin{array}{r}142 \\
92\end{array}$ & $\begin{array}{r}136 \\
88\end{array}$ & $\begin{array}{r}150 \\
97\end{array}$ & $\begin{array}{r}127 \\
83\end{array}$ & $\begin{array}{r}144 \\
94\end{array}$ & $\begin{array}{l}167 \\
108\end{array}$ & \\
\hline S.E. & & 13 & 16 & 13 & 18 & 14 & 15 & 11 & \\
\hline $\mathrm{P}$ value & & & $<0.5$ & $<0.1$ & $<0.3$ & $<0.05$ & $<0.5$ & $<0.4$ & \\
\hline
\end{tabular}

Urinary sodium excretion ( $\mu E q . / \min$.

\begin{tabular}{|c|c|c|c|c|c|c|c|c|c|}
\hline J. D. & $\begin{array}{l}239 \\
235\end{array}$ & 237 & 215 & 115 & 74 & 65 & 65 & 109 & \\
\hline L. L. & $\begin{array}{l}117 \\
125\end{array}$ & 121 & 125 & 110 & & & 87 & 117 & \\
\hline W. D. -1 & $\begin{array}{l}274 \\
222\end{array}$ & 248 & 242 & 221 & 175 & 158 & 121 & 181 & 176 \\
\hline W. D. -2 & $\begin{array}{l}167 \\
198\end{array}$ & 183 & 154 & 132 & 132 & & 100 & 124 & \\
\hline N. A. & $\begin{array}{l}233 \\
201\end{array}$ & 217 & 262 & 194 & 146 & 153 & 144 & 155 & 176 \\
\hline B. J. & $\begin{array}{l}291 \\
260\end{array}$ & 276 & 222 & 168 & 163 & 113 & 144 & 245 & 219 \\
\hline J. H. & $\begin{array}{l}284 \\
278\end{array}$ & 281 & 302 & 172 & 186 & 163 & 100 & 306 & 412 \\
\hline E. F. & $\begin{array}{l}413 \\
467\end{array}$ & 440 & 462 & 341 & 225 & 165 & 152 & 187 & 254 \\
\hline E. C. & $\begin{array}{l}127 \\
138\end{array}$ & 133 & 147 & 86 & & & 84 & 111 & \\
\hline $\begin{array}{c}\text { Mean } \\
\text { Per cent of control }\end{array}$ & & $\begin{array}{l}237 \\
100\end{array}$ & $\begin{array}{l}237 \\
100\end{array}$ & $\begin{array}{r}171 \\
72\end{array}$ & $\begin{array}{r}157 \\
66 \\
\end{array}$ & $\begin{array}{r}136 \\
57\end{array}$ & $\begin{array}{r}111 \\
47 \\
\end{array}$ & $\begin{array}{r}171 \\
72 \\
\end{array}$ & $\begin{array}{l}247 \\
104 \\
\end{array}$ \\
\hline S.E. & & 32 & 34 & 26 & 18 & 16 & 10 & 23 & 44 \\
\hline$P$ value & & & $>0.9$ & $<0.01$ & $<0.01$ & $<0.01$ & $<0.01$ & $<0.05$ & $<0.5$ \\
\hline
\end{tabular}


TABLE II-Continued

\begin{tabular}{|c|c|c|c|c|c|c|c|c|c|}
\hline \multirow[b]{2}{*}{ Patient } & \multicolumn{2}{|c|}{ Control } & \multicolumn{4}{|c|}{ Tourniquets on } & \multicolumn{3}{|c|}{ Tourniquets off } \\
\hline & Indiv. & Avg.* & $1 \dagger$ & 2 & 3 & 4 & 1 & 2 & 3 \\
\hline \multicolumn{10}{|c|}{ Urine volume $(\operatorname{ml} . / \min )}$. \\
\hline L. L. & $\begin{array}{l}11.0 \\
10.0\end{array}$ & 10.5 & 8.9 & 5.0 & & & 1.8 & 3.9 & \\
\hline W. D. -2 & 5.3 & 5.3 & 4.6 & 1.0 & & & 0.7 & 0.7 & \\
\hline B. J. & $\begin{array}{l}8.6 \\
8.3\end{array}$ & 8.5 & 7.3 & 2.6 & 1.0 & 0.9 & 1.3 & 3.6 & 6.5 \\
\hline H. W. & $\begin{array}{l}3.3 \\
4.1\end{array}$ & 3.7 & 3.4 & 2.2 & 1.2 & & 2.1 & 2.3 & \\
\hline E. F. & $\begin{array}{l}6.9 \\
8.0\end{array}$ & 7.5 & 8.9 & 4.3 & 1.8 & 1.6 & 2.1 & 2.5 & 4.5 \\
\hline J. H.-1 & $\begin{array}{l}9.3 \\
7.4\end{array}$ & 8.4 & 5.0 & 1.8 & 1.5 & 1.8 & 0.6 & 1.9 & 2.9 \\
\hline J. H. -2 & $\begin{array}{l}8.7 \\
8.1\end{array}$ & 8.4 & 3.2 & 1.3 & 1.1 & & · & & \\
\hline G. H. & $\begin{array}{l}4.6 \\
5.9\end{array}$ & 5.3 & 3.8 & 1.2 & 0.9 & & 0.6 & 1.2 & \\
\hline C. G. & $\begin{array}{r}9.8 \\
10.7\end{array}$ & 10.3 & 4.1 & 1.2 & 1.3 & & 0.6 & 0.5 & 1.2 \\
\hline $\begin{array}{c}\text { Mean } \\
\text { Per cent of control }\end{array}$ & & $\begin{array}{l}7.5 \\
100\end{array}$ & $\begin{array}{r}5.4 \\
72\end{array}$ & $\begin{array}{r}2.2 \\
29\end{array}$ & $\begin{array}{r}1.3 \\
17\end{array}$ & $\begin{array}{r}1.4 \\
19\end{array}$ & $\begin{array}{r}1.2 \\
16\end{array}$ & $\begin{array}{r}2.1 \\
28\end{array}$ & $\begin{array}{r}3.8 \\
51\end{array}$ \\
\hline S.E. & & 0.8 & 0.8 & 0.5 & 0.2 & 0.6 & 0.2 & 0.5 & \\
\hline$P$ value & & & $<0.05$ & $<0.001$ & $<0.001$ & $<0.01$ & $<0.001$ & $<0.001$ & $<0.1$ \\
\hline
\end{tabular}

ing to the methods described by Snedecor (13). Each tourniquet and post-tourniquet period has been compared with the corresponding control period and the group $\mathbf{P}$ values calculated accordingly.

\section{RESULTS}

Since in only two of the subjects were simultaneous data on all the above functions obtained, it is impossible to correlate cardiac output changes with renal function changes in individual studies. Furthermore, it is doubtful that the accuracy of the individual determinations would support such an attempt. For these reasons the results are presented collectively.

\section{Cardiac index}

The average control value for cardiac index was 3.5 ; the average during tourniquet periods was 2.8. In only two of the ten studies did cardiac index fail to fall following the application of tourniquets, thus leading to a statistically significant drop $(P<0.02)$. Repeat determinations were made following release of the tourniquets in all ten of these studies. In only one subject did cardiac index fail to rise following release of the tourniquets, and the average post-tourniquet value was 3.4. There was no significant difference between the pre- and post-tourniquet control values $(P>0.5)$. This finding conveys added importance to the drop during the tourniquet periods.

\section{Renal plasma flow}

During the first tourniquet period there was only a very slight fall in RPF $(P<0.2)$. However, a significant and progressive decline $(\mathrm{P}<$ $0.05, P<0.001$ and $P<0.01$ ) occurred during the last three tourniquet periods. This depression of RPF extended into the first period following release of the tourniquets $(P<0.02)$, although there was a return toward control level. During the second post-tourniquet period RPF returned to control level $(P>0.8)$. 


\section{Glomerular filtration rate and filtration fraction}

In all subjects except $L$. L., there was a slight fall in GFR during the periods of tourniquet application. The changes were minor, however, and did not approach the magnitude of those noted in RPF. Only during the fourth tourniquet period was the alteration of borderline statistical significance $(P<0.05)$. Following release of the tourniquets, GFR returned rapidly to control levels. These findings in the presence of the stated changes in RPF produced a marked rise in filtration fraction during the tourniquet periods.

\section{Urinary sodium excretion}

A highly significant depression of urinary sodium excretion $(\mathrm{P}<0.01, \mathrm{P}<0.01, \mathrm{P}<0.01)$ occurred beginning during the second tourniquet period and lasting through the first post-tourniquet period $(P<0.01)$. Not until the third period following release of the tourniquets did sodium excretion return to control level.

\section{Urine volume}

The most marked and prolonged alteration observed occurred in rate of urine flow. Depression of urine volume was noted during the first tourniquet period $(P<0.05)$, and this was highly significant $(P<0.001, P<0.001, P<$ 0.01 ) during the remaining tourniquet periods and through the second post-tourniquet period $(P<0.001, P<0.001)$. Urine volume began to rise during the second and third post-tourniquet periods, but even so did not return to control level.

The collective data from all of the experiments are presented in Figure 1.

\section{DISCUSSION}

Effective circulating blood volume and intracardiac pressures were not systematically determined during the above studies. However, it has been shown by others (14) that as much as $890 \mathrm{ml}$. of blood may be pooled in the extremities when venous tourniquets are applied to both thighs and one arm, thus leading to a considerable decrease in effective blood volume. Pooling of blood in the lower extremities also results in significant reductions in venous and right atrial pressures (15) and in right ventricular end-diastolic and pulmonary artery pressures (16).

In the present study a slight but statistically significant fall in cardiac output occurred with the application of tourniquets and a rise followed their release. The mechanism of this change in cardiac output is not immediately apparent and could involve several possible factors. First, congestion of the lower extremities per se might, through neurogenic and humoral mechanisms, produce the observed changes. Secondly, the diminished effective blood volume which results from the pooling of blood in the extremities could be the responsible factor. In order to investigate these two possibilities, venous tourniquets were applied to the thighs of two subjects, and in both studies a slight fall in cardiac output occurred during the period of application. Without releasing the tourniquets $1000 \mathrm{ml}$. of physiologic saline solution were given rapidly into the antecubital vein and the cardiac output rose above control level in both subjects. Upon release of the tourniquets cardiac output rose even higher. The data from one of these experiments

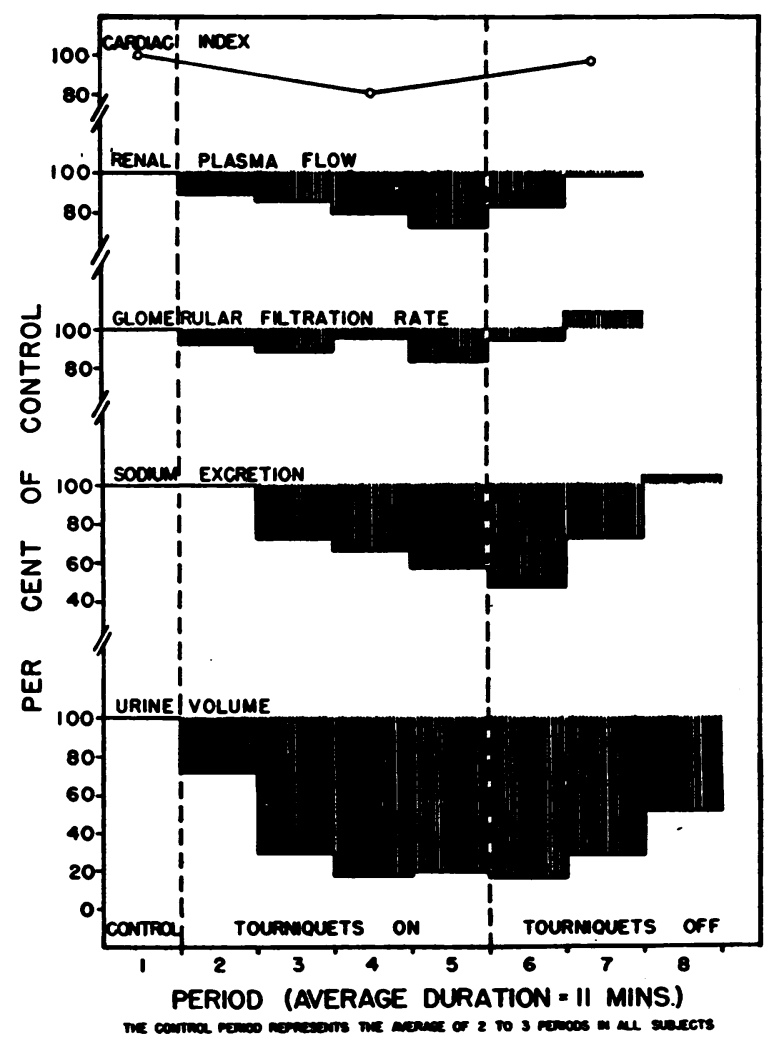

FIG. 1 


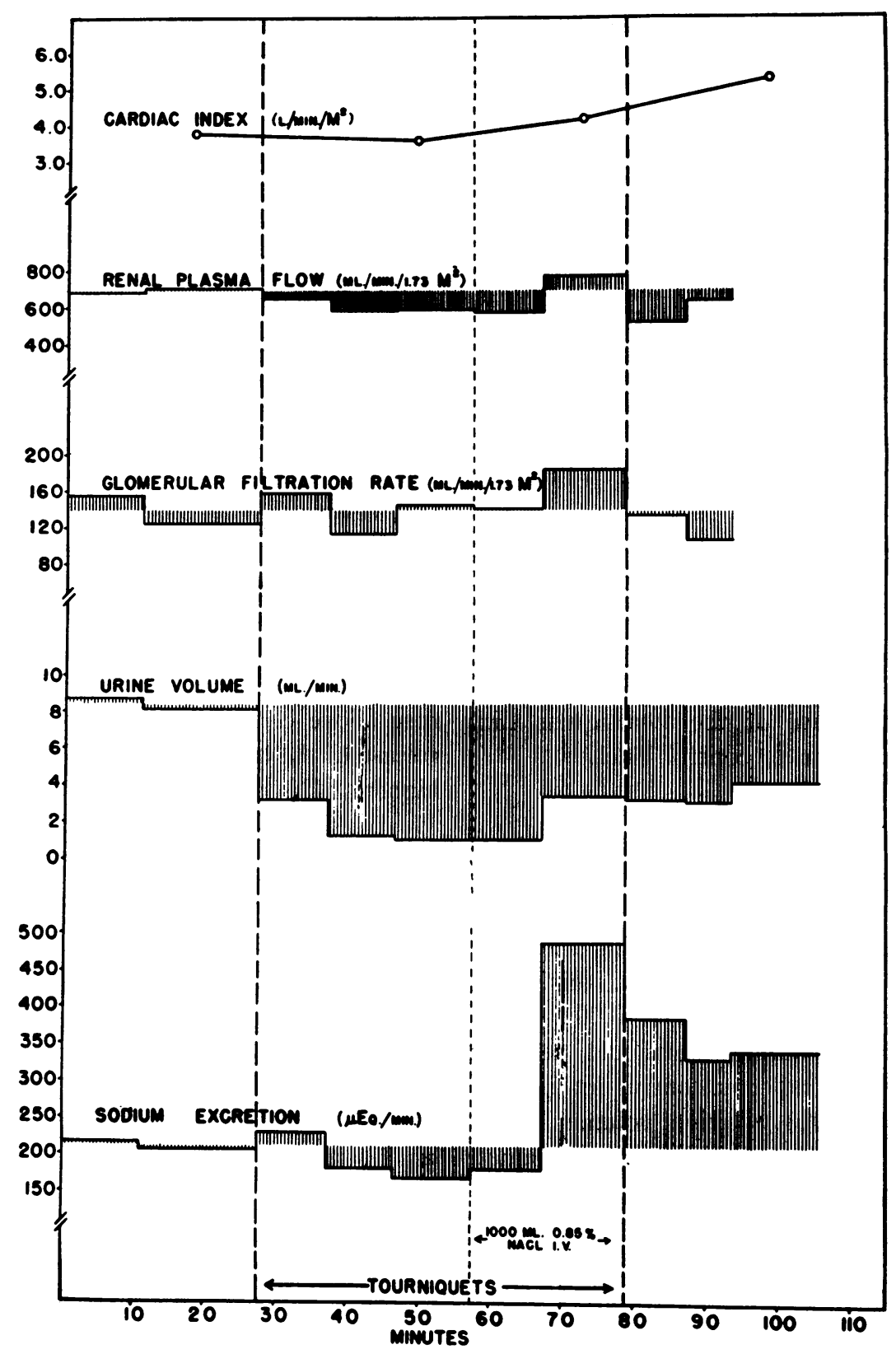

FIG. 2

are presented in Figure 2. These data indicate that by the rapid expansion of effective blood volume with physiologic saline solution, it is possible to return the cardiac output to normal or above normal even though the tourniquets remain in place. This suggests that venous congestion is not responsible for the fall in cardiac output as venous congestion would be increased, if anything, by this maneuver, and yet the cardiac output fell.
A third possibility is that decreased right atrial filling pressure causes the fall in cardiac output. Since right atrial pressure was not measured in the above studies, it is impossible to comment on this factor. In the final analysis these experiments do not answer the problem regarding the fall in cardiac output, but the data suggest that diminished effective blood volume is the responsible factor.

Similarly, the renal hemodynamic effects of the 
tourniquets could be produced as the result of congestion of the extremities per se or by the resulting decrease in effective blood volume. The experiment illustrated in Figure 2 favors the latter concept since rapid expansion of blood volume resulted in return of RPF and GFR to or toward normal. If, as postulated above, the decreased cardiac output during the tourniquet period is a result of diminished effective blood volume, then it is reasonable to state that the changes in renal hemodynamics were the direct result of diminished cardiac output. This seems likely since in many other situations a reduction in RPF has been noted in association with inadequate cardiac output. It is of interest to note that in severe congestive heart failure renal vasoconstriction produces a reduction in RPF out of proportion to the decrease in cardiac output (3). Furthermore, the renal vasoconstriction appears to be in the efferent arterioles as evidenced by the rise in filtration fraction. These same phenomena were observed in the present studies. In addition, the effects of the tourniquets upon renal hemodynamics (and upon sodium and water excretion) do not appear to be mediated through the sympathetic nervous system since they have also been observed in subjects following lumbodorsal sympathectomy (1). This has also been shown to be true of the renal hemodynamic changes of chronic congestive heart failure $(17,18)$.

The decrease in sodium excretion which occurred during the tourniquet periods must be secondary to increased tubular reabsorption since GFR showed only a slight fall. The rapidity with which the change in sodium excretion occurred is somewhat against an adrenocortical origin. Cerebral centers have been shown to affect sodium excretion in response to the upright posture, possibly as a result of lowered cerebral venous pressure since tourniquets about the neck inflated to subdiastolic pressures will abolish the response (19). Although these data present no definite evidence as to the cause of sodium retention during the tourniquet periods, it appears that diminished GFR plays at most a minor role.

The marked antidiuresis which occurred following application of tourniquets is similar to that observed in subjects who are tilted to the headup position. Brun, Knudsen, and Raaschou (4) suggested that increased secretion of the neuro- hypophysis as a result of the diminished effective blood volume might account for the antidiuresis seen in passive tilting, and, if true, it seems likely that this mechanism may be involved in the observations here reported.

\section{SUMMARY AND CONCLUSIONS}

1. The application of venous tourniquets to the thighs results in a slight but significant fall in cardiac output; highly significant falls in effective renal plasma flow, urine flow and sodium excretion, and a fall in glomerular filtration rate of borderline significance toward the end of the tourniquet period. With release of the tourniquets all of the above measured functions return to normal. The renal changes occur at different rates; urine flow slowly, sodium excretion more rapidly, and renal plasma flow quite promptly.

2. It is suggested that the decrease in cardiac output is most likely due to diminished effective blood volume and that the diminished cardiac output in turn leads to a fall in renal plasma flow (and questionably glomerular filtration rate). The inherent errors in the available methods and the lack of methods for performing rapid successive determinations of cardiac output and renal clearances make it impossible to be certain that decrease in renal plasma flow is a result of decreased cardiac output. However, the observed changes in renal function are similar to those in other situations where cardiac output is diminished, i.e., chronic congestive heart failure and shock.

3 . The cause of sodium retention is not clear but seems to be due to increased tubular reabsorption.

4. The marked antidiuresis which occurs after tourniquets are applied may be due to increased activity of the neurohypophysis, occurring as the result of diminished effective blood volume.

\section{ACKNOWLEDGMENTS}

The technical assistance of Misses Eloise Cavin and Virginia Whitner and Mrs. Marguerite Borders, Caroline Mashbourne and Sara Hutchins is gratefully acknowledged.

\section{REFERENCES}

1. Wilkins, R. W., Culbertson, J. W., Burrows, B. A., Tinsley, C. M., Judson, W. E., and Burnett, C. H., Antidiuresis and renal vasoconstriction following venous congestion of the limbs in normal, hypertensive and splanchnicectomized subjects. J. Clin. Invest., 1949, 28, 819. 
2. Chalmers, T. M., Lewis, A. A. G., and Pawan, G. L. S., The effect of the acute reduction of the glomerular filtration rate on sodium excretion in man. J. Physiol., 1952, 117, 218.

3. Merrill, A. J., Edema and decreased renal blood flow in patients with chronic congestive heart failure: evidence for "forward failure" as the primary cause of edema. J. Clin. Invest., 1946, 25, 389.

4. Brun, C., Knudsen, E. O. E., and Raaschou, F., Kidney function and circulatory collapse. Post-syncopal oliguria. J. Clin. Invest., 1946, 25, 568.

5. Smith, H. W., Goldring, W., and Chasis, H., The measurement of the tubular excretory mass, effective blood flow and filtration rate in the normal human kidney. J. Clin. Invest., 1938, 17, 263.

6. Bratton, A. C., and Marshall, E. K., Jr., A new coupling component for sulfanilamide determination. J. Biol. Chem., 1939, 128, 537.

7. Harrison, H. E., A modification of the diphenylamine method for determination of inulin. Proc. Soc. Exper. Biol. \& Med., 1942, 49, 111.

8. Alving, A. S., Rubin, J., and Miller, B. F., A direct colorimetric method for the determination of inulin in blood and urine. J. Biol. Chem., 1939, 127, 609.

9. Cournand, A., Riley, R. L., Breed, E. S., Baldwin, E. deF., and Richards, D. W., Jr., Measurement of cardiac output in man using the technique of catheterization of the right auricle or ventricle. J. Clin. Invest., 1945, 24, 106.

10. Stead, E. A., Jr., Warren, J. V., Merrill, A. J., and Brannon, E. S., The cardiac output in male subjects as measured by the technique of right atrial catheterization. Normal values with observations on the effect of anxiety and tilting. J. Clin. Invest., 1945, 24, 326.

11. Van Slyke, D. D., and Neill, J. M., The determination of gases in blood and other solutions by vacuum extraction and manometric measurement. I. J. Biol. Chem., 1924, 61, 523.

12. Peters, J. P., and Van Slyke, D. D., Quantitative Clinical Chemistry, Baltimore, Williams \& Wilkins Co. 1932, Vol. II.

13. Snedecor, G. W., Statistical Methods Applied to Experiments in Agriculture and Biology, ed. 4, Ames, Iowa, The Iowa State College Press, 1946.

14. Ebert, R. V., and Stead, E. A., Jr., The effect of the application of tourniquets on the hemodynamics of the circulation. J. Clin. Invest., 1940, 19, 561.

15. Warren, J. V., Brannon, E. S., Stead, E. A., Jr., and Merrill, A. J., The effect of venesection and the pooling of blood in the extremities on the atrial pressure and cardiac output in normal subjects with observations on acute circulatory collapse in three instances. J. Clin. Invest., 1945, 24, 337.

16. Estes, E. H., and McWhorter, R. L., Induced variations in pulmonary arterial pressure in man. Am. J. Physiol., 1949, 159, 568.

17. Mokotoff, R., and Ross, G., The effect of spinal anesthesia on the renal ischemia in congestive heart failure. J. Clin. Invest., 1946, 27, 335.

18. Turner, H., James, D. F., and Merrill, A. J., Studies on the mechanism of reduction of renal flow in heart failure. Preliminary report. Am. J. Med., 1948, 5, 619.

19. Lewis, J. M., Jr., Buie, R. M., Sevier, S. M., and Harrison, T. R., The effect of posture and of congestion of the head on sodium excretion in normal subjects. Circulation, 1950, 2, 822. 